\title{
USO DE MARCADORES MOLECULARES EN EL MEJORAMIENTO DEL FRIJOL ${ }^{1}$
}

\author{
James Kelly², Lucía Afanado ${ }^{3}$, Seott Haley 4 y Phillip Miklas 5
}

\begin{abstract}
RESUMEN
Uso de marcadores moleculares en el mejoramiento del frijol. Los métodos de mejoramiento para piramidar genes de resistencia a la enfermedades comprenden generalmente cruzas, retrocruzas, y cruzas de prueba encaminadas a verificar la presencia de una combinación deseada de estos genes en la progenie resultante. La acción epistática entre los genes de resistencia, sumada a limitaciones en el muestreo, y al trabajo que representan las cruzas de prueba, inciden finalmente en que no toda la progenie tenga la combinación deseada de genes. El procedimiento anterior vendría a ser más eficiente. si añadimos a esto el uso de marcadores moleculares ligados estrechamente a los genes de resistencia, seleccionando así indirectamente y en ausencia del patógeno, por la presencia de aquellos genes responsables por la resistencia. La presencia de este marcador no sería enmascarada por ninguna acción epistática, evento generalmente observado entre los genes de resistencia. Nuestro grupo de mejoramiento de frijol en Michigan State University, ha marcado exitosamente los genes Up-2, Ur-3, y el bloque de genes B-190, los cuales confieren resistencia a la roya del frijol. Este logro ha sido posible mediante el uso de marcadores moleculares del tipo RAPD (Random Amplified Polymorphic DNA), y poblaciones desarrolladas por retrocruzas. Estos marcadores moleculares nos ofrecen la oportunidad de piramidar de una manera más eficiente los genes de resistencia a la roya en genotipos específicos. Esta estrategia de mejoramiento incrementaría la durabilidad de estos genes.
\end{abstract}

\begin{abstract}
Molecular markers in bean (Phaseolus vulgaris L.) breeding. Plant breeding methods used to pyramid disease resistance genes generally involve crossing, backcrossing and test crosses in order to verify the presence of desirable combinations of these genes in the resulting progeny. The epistatic interaction between resistance genes combined with limitations of sample size and the work involved in test crossing results in progeny that do not always possess the desirable combination of genes. The entire procedure could be made more efficient through the use of molecular markers tightly linked to the resistance genes. Selection for the markers in the absence of the pathogen would result in the indirect selection of resistance genes. The expression of the marker is not masked by any epistatic interaction which commonly occurs with resistance genes. Our bean breeding/genetics group at Michigan State University have successfully tagged the Up-2, Ur-3 genes and the gene block B-190 which confer resistance to bean rust. This achievement has been possible through the use of molecular markers known as RAPD' s (Random Amplified Polymorphic DNA) and populations developed through backcrossing. These molecular markers offcr us the opportunity to pyramid rust rcsistance gene s into specific genotypes in the most efficient way. This breeding strategy will ensure the stability of the same resistance genes.
\end{abstract}

\section{INTRODUCCIÓN}

El mejoramiento de plantas de cultivos tradicionales, ha contribuido sin duda en la producción de nuevas variedades, con mayor y mejor rendimiento para los agricultores. Sin embargo, los mejoradores se han encontrado con limitaciones en la velocidad y precisión con que muchas de las características útiles pueden ser identificadas, seleccionadas, y utilizadas en sus programas de mejoramiento.

En los últimos años, los rápidos avances en la biología molecular vienen a proveer las herramientas necesa-

\footnotetext{
1 Presentado en la XXXIX Reunión Anual del PCCMCA en Guatemala, América Central. 28 de marzo - 3 de abril, 1993.

2 Associate Profesor, Crop and Soil Sciences. Mich. State Univ.. E. Lansing, MI 48824-1325.

3 Visiting Scientist, Crop and Soil Sciences, Mich. State Univ.. E. Lansing. MI 4H824-1325.

4 Assistant Professor, Dept. Plant Science, South Dakota State Univ.. Brookings, SD 57007.

5 Research Geneticist, Tropical Agricultural Research Station. P.O. Box 70. Mayaguez, PR 00681.
} 
rias para el estudio del mejoramiento genético de las plantas. Algunas de estas técnicas vienen a ser de utilidad en la caracterización del germoplasma y en la identificación y ubicación física en los cromosomas de características importantes. Estas técnicas han permitido el estudio del genoma de la planta por dos vías diferentes: primero con el análisis de proteínas e isoenzimas, y segundo con el análisis del ADN de la planta (RFLPs, RAPDs etc.). Estos análisis han contribuido finalmente a la identificación de marcadores moleculares asociados con características morfológicas, útiles en la determinación de:

a) variabilidad genética en bancos de germoplasma;

b) desarrollo de mapas genéticos; y

c) la identificación de genes específicos que puedan ser utilizados en los programas de mejoramiento.

Muchos investigadores de frijol hacen uso de estos marcadores en sus programas de mejoramiento. Bassett (1992) ha estado desarrollando marcadores morfológicos en frijol, encontrando estos en un número limitado y con muchas características de la hoja presentando efectos pleiotrópicos indeseables. De igual manera los trabajos de Koenig y Gepts (1989), y Sprecher (1988) con marcadores bioquÍmicos (proteínas, isoenzimas), han permitido la clasificación del frijol en dos grandes grupos de variabilidad genética, correspondientes a los dos centros de domesticación del frijol: el Andino y el Mesoamericano. Las isoenzimas, no obstante sus implicaciones biológicas, presentan limitaciones como marcadores debido a la poca variabilidad que ellas permiten detectar en cada grupo genético.

Trabajando de una manera independiente, los grupos de Vallejos et al (1992) y Nodari et al (1992), han logrado desarrollar un mapa del genoma del frijol, basado en el uso de marcadores moleculares del tipo RFLP (del inglés Restriction Fragment Length Polymorphism). Como criterios importantes en la selección del material genético, ambos grupos han considerado el uso de progenitores con origen evolutivo divergente y con características agronómicas contrastantes, hecho que influyó en la selección de líneas provenientes de grupos genéticos diferentes. El grupo de Nodari et al (1992), utilizó como pro- genitor un tipo silvestre de Phaseolus vulgaris, mientras que el grupo de Vallejos et al (1992) utilizó una línea mejorada con introgresión de $P$. coccineus. Los resultados obtenidos por Nodari et al (1992), indicaron un nivel de polimorfismo del $86 \%$ entre los grupos genéticos, siendo este mucho más bajo dentro de cada grupo genético; correspondiendo a 49\% en el Andino; y a 62\% en el Mesoamericano.

Considerando que en un programa de mejoramiento genético aplicado, un gran porcentaje del germoplasma utilizado pertenece a una misma raza, el nivel de polimorfismo dentro de cada raza es demasiado bajo como para ser utilizado en la selección dirigida por marcadores. Factores tales como el nivel tecnológico, el tiempo, el costo, y los riesgos asociados con el uso de marcadores del tipo RFLP, limitan su uso como herramientas de fácil adopción, en la selección rutinaria de características agronómicas útiles en un programa de mejoramiento.

Recientemente se ha desarrollado un tipo nuevo de marcadores moleculares, basados en la reacción en cadena de la enzima polimerasa (Polymerase Chain ReactionPCR). Este método permite la amplificación aleatoria de fragmentos de ADN con base en decanucleótidos de secuencia arbitraria, lo que genera un polimorfismo dominante conocido como RAPD (del inglés Random Amplified Polymorphic DNA)(Williams et al. 1991). La técnica utilizada para obtener marcadores del tipo RAPD es más rápida, menos sofisticada, y más apropiada para la filosofía de un programa de mejoramiento genético aplicado.

Nuestro programa de Mejoramiento y Genética del Frijol, de la Universidad Estatal de Michigan" viene desarrollando marcadores moleculares que ayuden en la selección de características agronómicas deseables. Uno de nuestros objetivos es el uso de marcadores moleculares que se encuentren estrechamente asociados con características determinadas por genes mayores de resistencia a enfermedades. Nuestro objetivo principal es la utilización de estos marcadores en la piramidización de genes de resistencia a la roya del frijol y con ello poder desarrollar un tipo de resistencia más estable o duradera. 


\section{MATERIALES Y MÉTODOS}

\section{Material genético}

Se desarrollaron líneas cuasi-isogenéticas (NILS) para tres genes o bloques de genes de resistencia a la roya del frijol: el gen Up-2, el bloque de genes B-190, y el gen Ur-3.

El alelo Up-2 fue transferido originalmente por retrocruzamiento, del frijol tipo habichuela Early Gallatin (Grupo genético Andino) al frijol blanco tipo navy C-20 (Grupo genético Mesoamericano) (Stavely et al 1991.). Eltrabajo de Stavely dio origen posteriormente a una población F2 de la sexta retrocruza $\left(\mathrm{RC}_{6} \mathrm{~F}_{2}\right)$, conformada por 84 individuos, segregando 3: 1 para el alelo Up-2. Los estudios de ligamiento parental entre los RAPDs y el alelo Up-2 fueron realizados en la misma población $\mathrm{RC}_{6} \mathrm{~F}_{2}$, utilizándose sus 84 individuos como fuentes de ADN en la elaboración de mezclas utilizadas para las pruebas de PCR.

El bloque genético B-190, fue transferido inicialmente del grupo genético Mesoamericano al grupo genético Andino por medio de retrocruzamiento (USOA and Expt.Sta.,Univ. Puerto Rico 1979). En los estudios con el bloque genético B-190 se utilizaron dos poblaciones segregantes: 1) población BBL47, conformada por 97 individuos $F_{2}$ originados de cuatro plantas individuales de la $\mathrm{F}_{1}$ de la sexta retrocruza, $\left(\mathrm{RC}_{6} \mathrm{~F}_{1}\right)$ producto del cruce BBL47*6/Green Giant 447/BI90; y 2) población Slenderette, conformada por 13 individuos $\mathrm{F}_{2}$ provenientes de una planta individual de la $F_{1}$ de la quinta retrocruza $\left(\mathrm{RC}_{5} \mathrm{~F}_{1}\right)$, producto del cruce Slenderette* 5/Eagle/Green Giant 447/B 190.

El gen Ur-3, fue encontrado originalmente en la variedad de frijol negro San Fernando de origen centroamericano (Costa Rica), y en su progenie de semilla blanca Nep-2. Los estudios de ligamiento entre el RAPD y el alelo Ur-3, fueron realizados en dos poblaciones: 1) po- blación A4513, conformada por 72 individuos $\mathrm{F}_{2}$ producto del cruce entre las líneas cuasi-isogenéticas 90T4042R/90T-4042S; y 2) población Olathe/ Sierra, conformada por 125 individuos $\mathrm{F}_{2}$.

El desarrollo de NILs, utilizados en los estudios del alelo Ur-3, fue realizado siguiendo una estrategia diferente a aquella utilizada con los genes Up-2 y el bloque genético B-190. El desarrollo de NILs se obtuvo través del proceso normal de autofecundación empleado normalmente en cultivos autógamos para el desarrollo de líneas y variedades. Un total de 10 a 20 plantas F3, por línea en cada población, fueron inoculadas y evaluadas siguiendo la metodología de Stavely et al (1989). Todas las inoculaciones fueron realizadas bajo condiciones de invernadero, y en campo e invernadero para la población Olathe/ Sierra.

La presencia o ausencia del gen Up-2, fue determinada utilizando la raza 50 de Uromyces appendiculatus, la cual causa reacción de hipersensibilidad (grado 2+, Stavely 1984.) en aquellos materiales con el alelo Up-2, y pústulas grandes (grado 5,6) en individuos sin el alelo Up-2.

La presencia o ausencia del bloque de genes B-190 y del gen Ur-3, fueron estudiadas utilizando la raza 53 de Uromyces appendiculatus. Los indi viduos, con el alelo B-190, fueron clasificados por su reacción a la raza 53 como pústulas pequeñas (grado 3 Stavely 1984.), y aquellos sin el alelo, por su reacción como pústulas grandes (grados 5 y 6). La presencia del alelo Ur-3 fue detectada en individuos con reacción de hipersensibilidad (grado 2+), y su ausencia en individuos presentando pústulas grandes (grados 5 y 6).

\section{Extracción de ADN}

Para la extracción de AON, a partir de cantidades grandes de tejido, se siguió la metodología de Nodari et al (1992) y Saghai-Maroof (1992), descritas previamente en los trabajos de Miklas et al (1993) y Haley et al 
(1993). Para cantidades pequeñas se siguió la metodología de Afanador et al (1993) descrita previamente en el trabajo de Haley et al (1994).

\section{Amplificación de ADN con la técnica de PCR}

Cada reacción de PCR fue iniciada con ADN genómico no digerido, un decanucleótido de secuencia arbitraria (primer), NTPs, $\mathrm{MgCI} 2$, solución tampón, y la enzima T AG-polimerasa estable al calor (Stoffel Fragment DNA polymerase, Perkin Elmer Cetus, Norwalk, Conn.). Los componentes en cada reacción fueron adicionados en las cantidades y procedimientos descritos previamente por Miklas et al (1993) y por Haley et al (1993).

La cantidad de ADN, utilizado como molde en al reacción inicial, es doblada en un proceso general denominado ciclo, el cual consiste de tres etapas: de naturalización, alineación, y extensión. En nuestro laboratorio hemos modificado las condiciones del ciclo de amplificación para el trabajo con ADN de frijol. Para el trabajo con el gen Up-2 se utilizaron un total de 47 ciclos, cada ciclo con las condiciones descritas por Miklas et al (1993). En los trabajos con el bloque de genes B-190 y el gen Ur-3, se realizaron algunas modificaciones, ello con el fin de mejorar la calidad dél producto final de amplificación y mayor reproducibilidad de los resultados. Se utilizaron un total de 37 ciclos, siendo las condiciones de amplificación las descritas por Haley et al (1994). Los productos de amplificación, para cada una de las condiciones y genes estudiados, fueron separados por electroforesis en geles de agarosa del $1.4 \%$ conteniendo bromuro de etidio.

La evaluación de los productos de amplificación, fue realizada teniendo en cuenta los siguientes criterios: los marcadores de tipo RAPD, se presentan como diferencias en el patrón de bandas, entre genotipos que se comportan como dominantes, a diferencia de los marcadores de tipo RFLP que son codominantes. El decanucleotido utilizado como fragmento iniciador (primer) para la amplificación del ADN original, genera ya sea patrones iguales o diferentes al ser separados estos por electroforesis. En el pri- mer caso se considera que el decanucleotido no es polimórfico por tanto es descartado, y en el segundo caso se considera polimórfico, y pasa a ser utilizado en la evaluación de las poblaciones segregantes, determinándose así su ligamiento al locus de interés, y por consiguiente su utilidad en el programa de mejoramiento.

\section{Procedimiento general}

En el análisis de marcadores del tipo RAPD de cada uno de los genes y poblaciones en estudio, se utilizaron mezclas de ADN genómico (Michelmore et al. 1991), conformadas de la siguiente manera: a) para el gen Up-2 se utilizaron dos tipos de mezclas compuestas por cantidades iguales de $\mathrm{ADN}$, la primera compuesta por $\mathrm{ADN}$ de tres individuos con el alelo Up-2, y la segunda de tres individuos sin el alelo Up-2. Las dos mezclas de ADN, representando líneas cuasi-isogenéticas contrastantes, fueron probadas con 167 decanucleotidos de secuencia arbitraria, evaluándose luego en las población segregante solo aquellos fragmentos amplificados por decanucleotidos en la mezcla de individuos resistentes. Aquellos marcadores RAPD; ligados al alelo dominante Up-2, fueron probados en muestras de germoplasma de frijol con el alelo o sin el alelo, con el fin de determinar su utilidad como marcadores genéticos.

La identificación de RAPDs para el bloque de genes B-190, fue realizada utilizando dos mezclas de ADN, consideradas cada una como poblaciones de líneas cuasiisogenéticas. Las mezclas estuvieron compuestas, una de ADN de individuos susceptibles (S), y la segunda de ADN de individuos resistentes (R). Las dos mezclas fueron formadas tanto para la población BBL47, como para la población Slenderette, y luego se probaron con 306 decanucleotidos aleatorios. Los análisis de cosegregación entre el marcador y los fenotipos $(\mathrm{R}, \mathrm{S})$ fueron realizados en submuestras de cada una de las poblaciones.

La identificación de marcadores tipo RAPD, asociados con el gen Ur-3, fue realizada mediante el uso de mezclas de ADN conformadas de igual manera que aque- 
llas para los genes Up-2 y el bloque genético B-190. Las mezclas estuvieron compuestas de cuatro individuos resistentes una, y de cuatro individuos susceptibles la segunda, esto para ambas poblaciones. Cada mezcla en cada población fue probada con 365 decanucleotidos aleatorios.

\section{RESULTADOS Y DISCUSIÓN}

El análisis de las mezclas de ADN, con o sin el gen Up-2 con un total de 167 decanucleotidos, resultaron en la amplificación de un total de 931 fragmentos de ADN, de los cuales solo uno fue polimórfico. Este fragmento correspondió al marcador RAPD OA14 1100 (amplificado por el decanucleotido 5'-TCTGTGCTGG-3"). Los estudios de recombinación entre el marcador OA14 1100 y el alelo dominante Up-2, no indicaron ningún recombinante dentro de una población $\mathrm{RC}_{6} \mathrm{~F}_{2}$ de 84 individuos segregantes. Estos resultados sugieren un ligamiento estrecho entre el marcador OA14 1100 y el gen de resistencia Up-2 (Miklas et al. 1992).

Germoplasma de los grupos genéticos Andino y Mesoamericano, con o sin el alelo Up-2, fue evaluado para determinar la presencia del marcador OA14 ${ }_{1100}$, Los resultados parecen indicar que el marcador es de origen Andino, ya que todas las líneas, con o sin el alelo Up-2 presentaron el marcador, mientras que este estuvo ausente en todo el germoplasma Mesoamericano, excepto en aquellas líneas, a la cuales el alelo Up-2 había sido incorporado. Estos resultados sugieren que el marcador OA14 ${ }_{1100}$, será mas útil para piramidar el alelo Up-2 y otros genes de resistencia a la roya, en germoplasma de origen mesoamericano, donde tradicionalmente el marcador no existe.

Haley et al (1994) identificaron dos marcadores del tipo RAPD, ambos ligados al bloque genético B-190, de resistencia a la roya. Uno de los marcadores fue identificado como $\mathrm{OFl0}_{970}$ (generado por el decanucleotido 5'GGAAGCTTGG-3') estrechamente ligado (2.15 \pm-1.5
cM) y en fase de acoplamiento con el bloque de resistencia. El segundo marcador RAPD, fue identificado como $\mathrm{OII}_{460}$ (generado por el decanucleotido 5'-AATGCGGGAG-3'), y más estrechamente ligado (también en fase de acoplamiento) al bloque de genes del marcador $\mathrm{OFl}_{970}$, Ningún recombinante fue detectado después de mapear una población de 97 individuos con el marcador 0I19 $9_{460}$, El análisis de una colección de genotipos de frijol resistentes y susceptibles, pertenecientes a los grupos gen éticos Andino y Mesoamericano, reveló una recombinación entre el marcador $\mathrm{OF} 10_{970}$ y el bloque genético. Hecho indicado por la presencia del marcador en algunos genotipos susceptibles. Nuestros resultados también indican una sola recombinación entre el RAPD $0 \mathrm{I} 19_{460}$ y el bloque de genes B-190, indicando que el marcador no se encuentra localizado dentro del bloque genético, sino que éste está situado entre el RAPD OF10 ${ }_{970}$ y el gen B-190.

Las mezclas de ADN extraído de plantas, con o sin el gen Ur-3, fueron probadas con 365 decanucleotidos, resultando en la identificación de un marcador de tipo RAPD. El marcador fue identificado como OK14 620 (amplificado por el decanucleotido 5'-CCCGCTACAC-3') y se encontró estrechamente ligado al gen de resistencia Ur-3. Ningún recombinante fue detectado dentro de la población A4513. Sin embargo tres recombinantes fueron detectados en la población de pintos Olathe/Sierra, ubicándose el marcador a una distancia de $2.23 \mathrm{cM}$ (Haley $e t$ al. 1994).

Como hecho importante se observó la reducción en la ocurrencia de positivos falsos, al usar NILs producto de solo dos selecciones (en la F6 y F8) para el gen de resistencia Ur-3, en lugar de NILs producto de selecciones sucesivas, necesarias en el retrocruzamiento. La reducción de positivos falsos, puede ser explicada de tres maneras diferentes: 1.- el uso de NILs provenientes de fuentes de germoplasma con divergencia genética más estrecha, donde se espera que el nivel de polimorfismo sea mucho menor; NILs altamente homozigotos (F8); 2.- reducción en el nivel de heterozigosidad producto de la reducción en la longitud del fragmento integrado, comparado a 
aquellos segmentos que no se encuentran ligados al gen de interés; y por último, la estrategia de mezclas, la que ha podido servir para enmascarar cualquier heterozigosidad residual presente entre los NILs originales.

\section{CONCLUSIONES}

Mientras que los marcadores OK14 620 y OI19 460 son útiles para seleccionar, por la presencia de genes de resistencia a la roya, en los dos grupos genéticos, los marcadores $\mathrm{OF} 10_{970}$ y $\mathrm{OA} 14_{1100}$ son útiles únicamente en un solo grupo genético. Con la excepción del RAPD OA14 1100 , la piramidizacion de genes (Ur-3 y B-190), basada en marcadores moleculares, será posible en el germoplasma Andino y ciertas razas Mesoamericanas de frijol en las cuales este bloque de genes de resistencia, tradicionalmente no existe.

La identificación del marcador OI19 460 , aparentemente sería útil en la transferencia facilitada por marcadores de la resistencia de B-190, entre grupos genéticos (del Mesoamericano al Andino), entre razas dentro del grupo genético Mesoamericano (de la raza Mesoamericana a la Durango) y dentro de la raza Mesoamericana, origen de este bloque de genes. La selección obtenida con la ayuda del marcador molecular $\mathrm{OK} 14_{620}$, asegurará el mantener el gen Ur-3 en las líneas de cruzamiento, aunque se presente epistasis debida a la presencia de otros genes de resistencia con acción más amplia.

La combinación efectiva de genes de resistencia a la roya, contra una raza simple del patógeno, se hace difícil debido a las interacciones epistáticas que ocurren frecuentemente entre estos genes. La selección basada en marcadores moleculares, se presenta como una alternativa a las cruzas de prueba requeridas para piramidar genes de resistencia a la roya que exhiben epistasiso Finalmente hemos mostrado la utilidad de los marcadores moleculares en la piramidización de genes de resistencia a la roya del frijol, y con ello poder desarrollar un tipo de resistencia más estable o duradera, a este patógeno tan variable.

\section{LITERATURA CITADA}

AFANADOR, L. K.; HALEY, S. D.; KELLY, J. D. 1993. Adoption of a "mini-prep" DNA extraction method for RAPD marker analysis in common bean. Ann. Rep. Bean Improv. Coop. 36: 10-11

BASSETT, M. J. 1992. Characterization and inheritance of four induced leaf mutants in common bean. J. Amer. Soc. Hort. Sci. 117:512-514.

HALEY, S. D.; MIKLAS, P. N.; STA VEL Y, J. R; BYRUM, J.; KELL Y, J. D. 1993. Identification of RAPD markers linked to a major rust resistant gene block in common bean. Theor. Appl. Genet, 86: 505-512.

HALEY, S. D.; AFANADOR, L. K. ; MIKLAS, P. N. ; STA VELY, J. R.; KELL Y, J. D. . 1994. Heterogeneous inbred populations are useful as sources of near-isogenic lines for RAPD marker localization. Theor. Appl. Genet (Accepted).

KOENIG, R.; GEPTS, P. 1989. Allozyme diversity in wild Phaseolus vulgaris: further evidence for two major centers of diversity. Theor. Appl. Genet. 78:809-817.

MICHEL MORE, R. W.; PARAN, I.; KESSELI, R V. 1991. Identification of markers linked to disease resistance genes by bulked segregant analysis: a rapid method to detect markers in specific agronomic regions using segregating populations. Proc. Natl. Acad. Sci.(U.S.A) 88:9828-9832.

MIKLAS, P. N., STA VEL Y, J. R ; KELL Y, J. D. 1993. Identification and potential use of a molecular marker for rust resistance in common bean. Theor. Appl. Genet. 86: 745749.

NODARI, R. O.; KOINANGE, E. M. R.; KELLY, J. D.; GEPTS, P. 1992. Towards an integrated linkage map of common bean. I. Development of genomic DNA probes and levels ofrestriction fragment length polymorphism. Theor. Appl. Genet. 84: 186-192.

SAGHAI-MAROOF, M. A., SOLIMAN, K. M., JORGENSEN, R. A.; ALLARD, R.W. 1984. Ribosomal DNA spacerIength polymorphism in barley: Mendelian inheritance, chromosomal location, and population dinamics. Proc. Natl. Acad. Sci (U.S.A) 81: 8014-8018. 
SPRECHER, S. L. 1988. Allozyme differentiation between gene pools in common bean (Phaseolus vulgaris L.) with special reference to Malawian germplasm. Ph.D. Thesis. Michigan State Univ.

STAVELY, J. R 1984. Pathogenic specialization in Uromyces phaseoli in the United States and rust resistance in beans. Plant Dis. 68:95-99.

STAVELY, J.R;STEADMAN,J.R.; MCMILLAN,R. T. 1989. New pathogenic variability in Uromyces appendiculatus in North America. Plant Dis. 73: 428-432.

STAVELY, J. R; KELLY,1. D.; GRAFTON, K. F. 1991. Release of seven erect, short vine navy bean germplasm lines, Be-
midak-Rust Resistant-1,-2,-3,-4,-5,-6, and -7. ARSUSDA Germplasm Release Notice.

USDA-SEA, AG. EXP. STN. UNIV. PUERTO RICO. 1979, The release of four black bean cultivars: B-128, B-190, B-351, and 2B-5-1. ARS-USDA Germplasm Release Notice.

VALLEJOS, C. E.; SAKIY AMA, N. S.; CHASE, C. D. 1992. A molecular marker-based linkage map of Phaseolus vulgaris L. Genetics 131:733-740.

WILLIAMS, J. G. K.; KUBELIK, K. J.; LIVAK, J. A; RAFALSKI; TINGEY, S. V. 1990. DNA polymorphism amplified by arbitrary primers are useful as genetic markers. Nucleic Acid Res.18:6531-6535. 